\title{
Correction to: Hybridization capture-based next-generation sequencing reliably detects FLT3 mutations and classifies FLT3- internal tandem duplication allelic ratio in acute myeloid leukemia: a comparative study to standard fragment analysis
}

\author{
Rong He $\mathbb{( i )}^{1} \cdot$ Daniel J. Devine ${ }^{1} \cdot$ Zheng Jin Tu $^{2,4} \cdot$ Ming Mai $^{1} \cdot$ Dong Chen ${ }^{1} \cdot$ Phuong L. Nguyen ${ }^{1}$. \\ Jennifer L. Oliveira ${ }^{1} \cdot$ James D. Hoyer $^{1} \cdot$ Kaaren K. Reichard $^{1} \cdot$ Paul L. Ollila $^{1} \cdot$ Aref Al-Kali $^{3} \cdot$ Ayalew Tefferi $^{3}$. \\ Kebede H. Begna ${ }^{3}$ - Mrinal M. Patnaik ${ }^{3}$ - Hassan Alkhateeb ${ }^{3}$ - David S. Viswanatha ${ }^{1}$
}

Published online: 7 October 2019

(c) The Author(s) 2019. This article is published with open access

\section{Correction to: Modern Pathology} https://doi.org/10.1038/s41379-019-0359-9

This article was erroneously published with standard licence and copyright, but it is in fact published with open access, so has a CC BY licence and the copyright line is 'The Author(s)'. This has been updated in the original article.
Open Access This article is licensed under a Creative Commons Attribution 4.0 International License, which permits use, sharing, adaptation, distribution and reproduction in any medium or format, as long as you give appropriate credit to the original author(s) and the source, provide a link to the Creative Commons license, and indicate if changes were made. The images or other third party material in this article are included in the article's Creative Commons license, unless indicated otherwise in a credit line to the material. If material is not included in the article's Creative Commons license and your intended use is not permitted by statutory regulation or exceeds the permitted use, you will need to obtain permission directly from the copyright holder. To view a copy of this license, visit http://creativecommons. org/licenses/by/4.0/.
The original article can be found online at https://doi.org/10.1038/ s41379-019-0359-9.

Rong He

He.Rong@mayo.edu

1 Division of Hematopathology, Mayo Clinic College of Medicine, Rochester, MN, USA

2 Biomedical statistics and informatics, Mayo Clinic College of Medicine, Rochester, MN, USA

3 Division of Hematology, Mayo Clinic College of Medicine, Rochester, MN, USA

4 Present address: Department of Laboratory Medicine, Cleveland Clinic, Cleveland, OH, USA 